\title{
PERÍCIA FONOAUDIOLÓGICA: CONHECIMENTO E ATUAÇÃO DOS PROFISSIONAIS DA FONOAUDIOLOGIA DE DOIS ESTADOS DO BRASIL
}

\section{Speech expertise: knowledge and the performance by professionals of speech, language and hearing science in two Brazilian states}

Leslie Palma Gorski ${ }^{(1)}$, Suleny Gomes Lopes ${ }^{(2)}$, Etienne Barbosa da Silva ${ }^{(3)}$

\begin{abstract}
RESUMO
Objetivo: analisar o conhecimento e a atuação em perícia fonoaudiológica de profissionais atuantes em dois Estados brasileiros. Método: o estudo foi realizado com 71 fonoaudiólogos de ambos os gêneros com idade entre 21 a 52 anos, atuantes nos estados da Bahia e Paraná. O conhecimento e atuação na perícia fonoaudiológica foram avaliados por meio da aplicação de um questionário. Resultados: verificou-se que $94,4 \%$ dos indivíduos pesquisados são do gênero feminino, com média de idade de 28 anos, formados em sua maioria há no máximo cinco anos, sendo que $59,2 \%$ destes já possuem pós-graduação. A grande maioria dos indivíduos não teve contato com perícia durante a graduação e poucos buscaram cursos sobre o tema depois de formados. Analisando em conjunto os demais dados coletados, constatou-se que o conhecimento da população estudada é insuficiente nessa área e que a atuação do fonoaudiólogo em perícia é bastante restrita. Conclusão: a pesquisa e a inserção de matéria específica sobre Perícia Fonoaudiológica nos cursos de graduação e/ou pós-graduação são de suma importância, pois a perícia em fonoaudiologia mostrou-se um tema pouco abordado, fazendo com que os profissionais tenham um escasso conhecimento sobre o mesmo, levando a uma atuação muito restrita dentre os profissionais da área.
\end{abstract}

DESCRITORES: Fonoaudiologia; Conhecimento; Área de Atuação Profissional; Competência Profissional; Prova Pericial

\section{INTRODUÇÃO}

A Fonoaudiologia é a ciência da saúde responsável pela promoção, diagnóstico, orientação,

(1) Fonoaudióloga; Programa de Pós-graduação (Especialização) em Gestão em Fonoaudiologia: Perspectiva Empresarial pela Faculdade de Estudos Administrativos de Minas Gerais - FEAD, Belo Horizonte, MG, Brasil.

(2) Fonoaudióloga; Programa de Pós-graduação (Especialização) em Gestão em Fonoaudiologia: Perspectiva Empresarial pela Faculdade de Estudos Administrativos de Minas Gerais - FEAD, Belo Horizonte, MG, Brasil.

(3) Fonoaudióloga; Docente da Pós-graduação em Gestão em Fonoaudiologia: Perspectiva Empresarial - Faculdade de Estudos Administrativos de Minas Gerais - FEAD, Belo Horizonte, MG, Brasil.

Trabalho realizado na Faculdade de Estudos Administrativos de Minas Gerais - FEAD - Belo Horizonte, MG, Brasil

Conflito de interesses: inexistente tratamento, monitoramento e aperfeiçoamento de questões relacionadas à comunicação humana, tais como audição periférica e central, função vestibular, linguagem oral e escrita, articulação da fala, voz, fluência, deglutição e sistema miofuncional orofacial e cervical. É uma ciência ainda nova se comparada a outras profissões da saúde, mas com uma possibilidade de atuação bem ampla, podendo ser realizada junto a recém-nascidos até a terceira idade. Está presente em hospitais, maternidades, atendimento ambulatorial, asilos, na educação, indústrias, meios de comunicação e arte, estética e justiça, sendo esse último o foco dessa pesquisa ${ }^{1}$.

No âmbito judicial encontra-se a perícia, que tem como objetivo esclarecer determinados aspectos técnicos, por isso é conceituada como um exame de situações ou fatos, que dizem respeito a coisas e pessoas, realizado por especialista na área que lhe 
é submetida². Trata-se de um elemento subsidiário, emanado de um órgão auxiliar da justiça para a valoração ou solução da prova destinada à descoberta da verdade. A autoridade judicial, para decidir causas dentre as mais distintas e complexas, precisaria conhecer todas as especialidades do saber humano, não sendo isso possível, justifica-se assim a necessidade de a Justiça recorrer a profissionais especialistas nas diferentes áreas de conhecimento ${ }^{3,4}$.

A atuação profissional pericial pode dar-se em cinco grandes áreas: administrativa, judicial, criminal, assistência técnica e extrajudicial.

A perícia administrativa pode acontecer em órgãos públicos, como no caso de requerimento de benefício previdenciário, onde o trabalhador deve passar por uma perícia para conseguir a benfeitoria; em órgãos privados, como em seguradoras particulares, onde o cliente deve passar por uma perícia para receber a indenização contemplada em sua apólice. Vale ressaltar que nesse tipo de perícia não há um modelo normativo a ser seguido5.

$O$ perito que atua na área administrativa efetua perícias de convênios e demandas internas em instituições públicas ou privadas, como em avaliações admissionais de profissionais que irão trabalhar em funções de risco vocal ou auditivo, e participação em juntas médicas periciais de capacidade laborativa. Neste caso o termo perícia não está bem aplicado uma vez que a palavra remete ao setor jurídico, cuja realização somente pode ser determinada por autoridade judicial. Em se tratando de convênios de saúde, a palavra mais adequada seria "avaliação" ou "auditoria"6, 7 .

A literatura aponta que a perícia judicial é um meio de prova que objetiva esclarecer o juiz sobre desacordos que envolvam conhecimentos técnicos. É produzida num processo judicial para decidir fatos controversos trazidos pelas partes, como por exemplo, um funcionário que aciona a justiça para requerer indenização por perda auditiva induzida por ruído ocupacional. Neste caso, o juiz poderá nomear um profissional especializado na área para averiguar e provar os fatos, dando seu parecer ${ }^{5}$.

A perícia criminal pode ser Cível ou Federal. Normalmente é realizada por funcionário público que atua exclusivamente para o Estado, como nos casos de necessidade de identificação do indivíduo pela voz, seja por meio de gravações telefônicas, de áudio ou vídeo ${ }^{7}$. A voz de um sequestrador, por exemplo, pode ser identificada para comprovar a participação do mesmo no crime.

A assistência técnica, por sua vez, ocorre quando as partes envolvidas no processo solicitam a participação de um profissional para acompanhar o trabalho realizado pelo perito judicial. $\mathrm{O}$ assistente técnico busca defender os interesses da parte que o contratou e, neste caso, pode apresentar quesitos para serem respondidos pelo perito e ainda acompanhar os procedimentos realizados pelo mesmo, além de poder oferecer seu parecer crítico ao laudo do perito ${ }^{8}$.

E por fim, a perícia extrajudicial é aplicada em ocasiões em que é desnecessária a presença do Estado por meio do Poder Judiciário. Segue o mesmo princípio da perícia judicial, porém se diferencia quando se fala do assistente técnico, pois se as partes concordarem em aceitar o resultado apresentado pelo perito, não será necessária a participação do assistente técnico, tornando-se um processo mais rápido e barato que a perícia judicial ${ }^{7}$.

Um profissional é considerado perito quando se especializa em determinado ramo ou assunto, ou seja, tem experiência e/ou habilidade em determinada atividade 9 .

O perito é partícipe e co-responsável pela sentença à qual chegará o juiz posteriormente, e que influenciará a vida dos seres humanos. Deve-se sentir seguro, para atuar de forma imparcial, registrando a realidade de forma neutra e sem favores, relatando-a de modo direto e inequívoco para se chegar à conclusão ${ }^{10}$.

A atuação de um perito é limitada, pois ele não julga, não defende e não acusa. Compete ao perito examinar e relatar fatos de natureza específica e caráter permanente de esclarecimento necessário em um processo 6 .

Dessa forma, conclui-se que todo profissional pode ser perito $^{6}$, afirmativa esta ratificada no artigo 145, parágrafos $1^{\circ}, 2^{\circ}$ e $3^{\circ}$ do Código de Processo Civil (CPC), que rege que o perito deve ser um profissional de nível universitário com inscrição em seu respectivo órgão de classe. Sendo assim, o Fonoaudiólogo é um profissional que está apto a realizar perícia que se relaciona ao seu campo de conhecimento, direito este não apenas assegurados pelo CPC, como também pelo Código de Ética do Profissional Fonoaudiólogo que prevê em seu art. 25: "Qualquer Fonoaudiólogo, no exercício de sua profissão, pode ser nomeado perito para esclarecer a Justiça em assuntos de sua competência". E não obstante o Conselho Federal de Fonoaudiologia editou a Resolução no 214/98 que delibera: " $E$ permitido ao Fonoaudiólogo atuar judicial ou extra-judicialmente como perito em assuntos de sua competência" .

Pesquisas demonstram que o mercado de atuação pericial e áreas afins ampliam-se significantemente a cada dia; mas se observam poucas incursões da Fonoaudiologia Brasileira no campo da perícia. Isto nos dá a impressão de ser uma área 
nova, porém, na realidade é apenas uma área pouco difundida e explorada pelos fonoaudiólogos ${ }^{11}$.

Sendo assim, este estudo busca analisar o conhecimento e a atuação em perícia de fonoaudiólogos em dois Estados brasileiros. Espera-se contribuir na divulgação desta área de atuação a fim de ampliar a inserção deste profissional no campo de atuação em perícia.

\section{MÉTODO}

Trata-se de um estudo incluindo 71 fonoaudiólogos formados, atuantes nos Estados da Bahia e Paraná, selecionados aleatoriamente, sem restrições quanto ao tempo e área de atuação profissional e que aceitaram responder ao questionário abaixo sobre seu conhecimento e atuação em perícia fonoaudiológica, (Figura 1).

\section{Dados de Identificação}

Nome:

Sexo: Idade:

Ano de graduação:

lização:

Se sim, em qual área?

Cidade(s) que atua:

Questionário

1. Em sua graduação teve contato com Perícia Fonoaudiológica?

口 Sim $\square$ Não

2. Se sim, através de que?

$\square$ Palestra

Disciplina no curso de graduação

$\square$ Outro:

3. Já fez algum curso nessa área?

口 Sim $\square$ Não

4. Se sim, quantos e há quanto tempo?

5. No que se refere à titulação, o que você acha que o fonoaudiólogo precisa ter para atuar como perito? Marque quantas alternativas desejar

$\square$ Graduação em que área, com registro em conselho de classe

Especialização em qualquer área da Fonoaudiologia

Especialização em Perícia

$\square$ Tenho dúvidas a este respeito

6. Em quais áreas acha que o Fonoaudiólogo pode atuar como Perito?

$\square$ Audiologia

Linguagem

Motricidade Orofacial

- Saúde Pública

$\square$ Voz

- Nenhuma delas, já que o fonoaudiólogo não tem respaldo legal para atuar como perito

7. Se acha que o fonoaudiólogo pode trabalhar como perito em alguma(s) área(s) da Fonoaudiologia, exemplifique como:

8. Já atuou (ou ainda atua) como perito?

口 Sim $\square$ Não 
9. Se sim, em que tipo de perícia?

口 Judicial

Extrajudicial

Administrativa

Assistência técnica

口 Não sei dizer

10. Já foi solicitado(a) a fazer laudos/pareceres periciais?

- Não, nunca fui convocado(a), mas se fosse, atenderia prontamente o pedido.

- Não, nunca fui convocado(a), e se fosse recusaria, pois não tenho experiência na área.

- Sim, já me convocaram, mas como não tinha experiência na área, recusei o pedido.

- Sim, mas fui convocado(a) poucas vezes.

Sim, sempre sou convocado(a).

$\square$ Outro:

11. Se já foi convocado(a), em qual área(s) foi?

12. Como foi convocado(a)?

r Fui chamada aleatoriamente por ser fonoaudióloga.

- Fui chamada por ser a fonoaudióloga da empresa.

- Fui chamada porque divulguei minha disposição aos Juízes da minha cidade.

Fui chamada por ser a única fonoaudióloga da minha cidade.

$\square$ Outro:

13. Em relação ao mercado de trabalho, para que o fonoaudiólogo seja inserido na área pericial, você acredita que:

Deve ser concursado para atuar como perito.

$\square$ Deve divulgar sua atuação junto aos juízes de sua cidade.

$\square$ Outro:

Figura 1 - Questionário sobre Perícia Fonoaudiológica

Considerou-se neste estudo, como variáveis dependentes o conhecimento sobre perícia dos fonoaudiólogos atuantes nos dois estados e variáveis independentes a história ocupacional (tempo de trabalho, área de atuação e curso na área da pesquisa) e sócio-demográfica (idade e localidade e remuneração por serviço prestado em perícia).

A pesquisa foi aprovada pelo Comitê de Ética da instituição de origem, com protocolo de número $118 / 09$. Todos os participantes concordaram em participar voluntariamente, estando cientes e de acordo com os procedimentos, confirmando que estes não trouxeram nenhum prejuízo pessoal ou profissional. O Termo de Consentimento Livre e Esclarecido (TCLE) foi realizado segundo os critérios estabelecidos pela Resolução 196/96 do Conselho Nacional de Saúde ${ }^{12}$.

Para análise estatística foi utilizado o Teste Qui-quadrado com nível de significância fixado em $0,05(5 \%)$.

\section{RESULTADOS}

Foram envolvidos no estudo 71 fonoaudiólogos, sendo $47(66,2 \%)$ atuantes no Estado da Bahia e 24 $(33,8 \%)$ no Paraná. Do total da amostra, 67 (94,4\%) indivíduos são do gênero feminino e quatro (5,6\%) do gênero masculino. A faixa etária da população variou de 21 a 52 anos, com média de 28,9 anos e desvio-padrão de 6,8 anos. A variação quanto ao tempo de formação dos profissionais foi: 51 profissionais formados até cinco anos $(71,8 \%) ; 11$ $(15,5 \%)$ de seis a 10 anos e nove $(12,7 \%)$ há mais de 10 anos. A maioria dos participantes, 44 (62\%), têm curso de pós-graduação, sendo este achado estatisticamente significante se comparado a idade dos mesmos, ou seja, a proporção daqueles que têm curso de especialização é significantemente maior para os indivíduos com idade de 30 anos ou mais (Tabela 1) 
Tabela 1 - Relação entre idade e curso de especialização ( $N=71)$

\begin{tabular}{|c|c|c|c|}
\hline \multirow{2}{*}{ IDADE } & \multicolumn{2}{|c|}{ ESPECIALIZAÇÃO } & \multirow{2}{*}{$\mathbf{p}$} \\
\hline & Não & Sim & \\
\hline Menos de 30 anos & 27 & 25 & $0,0001^{*}$ \\
\hline 30 anos ou mais & - & 19 & \\
\hline
\end{tabular}

Fonte: A autora.

Nota: Teste Qui-quadrado $=p<0,05$.

Os cursos de pós-graduação distribuem-se entre as cinco grandes áreas da Fonoaudiologia e algumas áreas afins, sendo a Audiologia a área mais citada (Tabela 2).

Tabela 2 - Indivíduos que realizaram curso de pós-graduação, divididos por área (N=44 )

\begin{tabular}{lcc}
\hline Área da Pós-Graduação & $\begin{array}{c}\text { Quantidade de } \\
\text { citações }\end{array}$ & $\%$ \\
\hline Audiologia & 21 & 47,7 \\
M.O. & 6 & 13,6 \\
Voz & 6 & 13,6 \\
Saúde Coletiva & 3 & 6,8 \\
Linguagem & 3 & 6,8 \\
Neurologia & 3 & 6,8 \\
Saúde Mental & 1 & 2,3 \\
Educação Especial & 1 & 2,3 \\
\hline
\end{tabular}

Fonte: A autora.

No que se refere ao conhecimento adquirido sobre perícia durante a graduação, dos 71 indivíduos pesquisados, $63(88,7 \%)$ referiram nenhuma informação e apenas oito (11,3\%) obtiveram algum conhecimento sobre o assunto, todos com menos de cinco anos de formação, sendo quatro do estado da Bahia e quatro do Paraná.

Dos que referiram ter recebido algum conhecimento, seis $(75 \%)$ foram por meio de palestras, um $(12,5 \%)$ em estágio e um $(12,5 \%)$ obteve informação em sala de aula. Quando questionados se já realizaram algum curso na área, $64(90,1 \%)$ não realizam nenhum curso e apenas sete $(9,9 \%)$ referiram ter realizado, sendo esta procura maior pelos profissionais da Bahia, representado por seis profissionais. Observa-se que dos sete profissionais que realizaram algum curso, todos o fizeram recentemente, entre zero a cinco anos

Quando questionados sobre a titulação mínima necessária para o profissional atuar como perito, foi observado que a maioria acredita que é necessário ter especialização em perícia $(32,4 \%)$, estando os demais resultados apresentados na Tabela 3.
Com relação ao conhecimento que os participantes possuem sobre as áreas em que o fonoaudiólogo pode atuar como perito, 100\% pontuaram alguma área, sendo que 29 (40,85\%) participantes responderam todas as áreas, seguido de Audiologia e Voz, relatado por 17 (23,94\%) participantes. Os demais se dividiram entre as cinco grandes áreas da Fonoaudiologia. Porém, quando Ihes foi questionado se saberiam exemplificar as formas como poderiam atuar nas diversas áreas, $23(32,4 \%)$ indivíduos não souberam exemplificar.

Em relação à atuação em perícia fonoaudiológica, apenas seis $(8,5 \%)$ indivíduos referem ter atuado na área, sendo desses seis, dois como assistente técnico $(54,5 \%)$ dois como perito judicial e assistente técnico (54,5\%), um como perito judicial $(16,7 \%)$ e um como perito extrajudicial $(16,7 \%)$. Quando comparada essa atuação com a idade dos participantes, verifica-se que existe dependência significante entre idade e atuação como perito, ou seja, a proporção dos que atuaram como perito é significantemente maior no grupo de idade 30 anos ou mais. (Tabela 4) 
Tabela 3 - 0 que o fonoaudiólogo precisa ter para atuar em perícia ( $\mathrm{N}=71$ )

\begin{tabular}{lcc}
\hline Pré-requisito & $\begin{array}{c}\text { Quantidade de } \\
\text { citações }\end{array}$ & $\%$ \\
\hline Somente especialização em Perícia & 23 & 32,4 \\
Tem dúvida sobre o assunto & 13 & 18,3 \\
Graduação com registro em conselho de classe & 12 & 16,9 \\
Graduação com registro em conselho de classe, especialização & 8 & 11,3 \\
em qualquer área da Fonoaudiologia e Especialização em Perícia & 5 & 7,0 \\
Graduação com registro em conselho de classe e especialização & 5,0 \\
em Perícia & 5 & 5,6 \\
Graduação com registro em conselho de classe e especialização & 4 & 1,4 \\
em qualquer área da Fonoaudiologia & 1 & \\
Esmente especialização em qualquer área da Fonoaudiologia & & \\
especialização em qualquer área da Fonoaudiologia e & & \\
\hline
\end{tabular}

Fonte: A autora.

Tabela 4 - Relação entre idade e atuação como perito

\begin{tabular}{lccc}
\hline \multirow{2}{*}{ IDADE } & \multicolumn{2}{c}{ ATUAÇÃO COMO PERITO } & \multirow{2}{*}{$\mathbf{p}$} \\
\cline { 2 - 3 } & Não & Sim & \multirow{2}{*}{$0,0011^{*}$} \\
\hline Menos de 30 anos & 51 & 1 & \multirow{2}{*}{ 30 anos ou mais } \\
\hline
\end{tabular}

Fonte: A autora.

Nota: Teste Qui-quadrado $=p<0,05$.

Analisando as respostas dos fonoaudiólogos com relação à execução de laudos/ pareceres periciais, observou-se que apenas um $(1,4 \%)$ fonoaudiólogo sempre é convocado, cinco $(7 \%)$ são convocados poucas vezes, quatro $(5,6 \%)$ já foram solicitados, mas como não tinham experiência na área recusaram o pedido, 27 (38\%) nunca foram solicitados, mas se o fossem atenderiam prontamente o pedido e $34(47,9 \%)$ nunca foram solicitados, mas se o fossem recusariam, pois consideram não ter experiência na área.

Considerando os dados coletados sobre convocação para atuação em perícia, observou-se que $10(14,1 \%)$ indivíduos responderam que sim, sendo que destes 10 , quatro $(40 \%)$ foram chamados por indicação de outros profissionais, três (30\%) aleatoriamente por ser fonoaudiólogo, dois $(20 \%)$ foram chamados por serem fonoaudiólogos da empresa e apenas um (10\%) foi chamado por ter divulgado sua atuação junto aos juízes de sua cidade.

\section{DISCUSSÃO}

Os dados do presente estudo indicam a prevalência de profissionais do gênero feminino, confirmando uma realidade brasileira apontada também em pesquisas realizadas no Estado da Paraíba e na cidade de Salvador na Bahia onde se encontrou predominância de profissionais do gênero feminino atuando em Fonoaudiologia ${ }^{13,14}$.

Com relação à idade e tempo de formação, encontrou-se uma idade média de 28,9 anos com tempo médio de graduação de 4,9 anos, sendo estes resultados também encontrados em uma pesquisa realizada com Fonoaudiólogos da Bahia ${ }^{13}$.

No que se refere aos dados de que a maioria dos participantes, mesmo com pouco tempo de formação, já tem curso de pós-graduação, revela o interesse dos profissionais em buscar aprimoramento, coincidindo com os dados achados em pesquisa realizada no Estado da $\mathrm{Bahia}^{13}$. Com relação ao predomínio de pós-graduação entre os indivíduos com 30 anos ou mais não foram encontrados estudos na literatura que possibilitassem discutir essa relação. 
O estudo em questão revela que apenas $8,5 \%$ dos profissionais pesquisados atuam ou já atuaram em perícia confirmando o apontamento da literatura de que o mercado de atuação em perícia vem ampliando-se de forma significante e constante, porém observam-se poucas investidas da Fonoaudiologia brasileira na área ${ }^{11}$.

Dos 71 indivíduos pesquisados, a grande maioria $(88,7 \%)$ não teve contato com perícia durante a graduação, estando de acordo com uma pesquisa realizada nas Instituições de Ensino Superior do Sul do Brasil, onde $75 \%$ das Instituições dessa região não oferecem em seus currículos subsídios para atuação em Perícia Fonoaudiológica.

No que tange aos aspectos referentes ao conhecimento dos participantes sobre Perícia, como área de atuação fonoaudiológica e a titulação necessária para qualquer profissional atuar na área, observou-se pouco conhecimento por parte dos indivíduos pesquisados, vindo de acordo com a literatura, que afirma que a maioria dos profissionais da área não se sentem capazes de elencar as principais atribuições de um fonoaudiólogo perito e suas possibilidades de atuação no mercado ${ }^{7}$.

Os resultados deste estudo evidenciam a perícia judicial nas áreas audiológica e vocal no âmbito ocupacional, como mais conhecidas confirmando os dados da literatura que apontam que fonoaudiólogos relacionam a atuação pericial apenas no âmbito judicial, na área de audiologia ocupacional, desconhecendo a participação do fonoaudiólogo em perícias administrativas, como nas juntas médicas periciais em serviço público, por exemplo ${ }^{7}$.

Este estudo constatou que a experiência na área da Perícia em Fonoaudiologia ainda encontra-se bem restrita, pois apenas $8,5 \%$ dos profissionais questionados atuam ou já atuaram na área o que justifica, também, o desconhecimento dos profissionais sobre $o$ assunto.

Quanto à qualificação para atuação na área pericial, a grande maioria $(83,1 \%)$ demonstrou desconhecer o assunto ou acreditar que o profissional necessita de outros títulos, além da graduação e registro em conselho de classe para atuar, ratificando o desconhecimento dos profissionais sobre a área e suas legislações, pois de acordo com a literatura, para a atuação do profissional como perito, é necessário apenas a graduação e inscrição junto ao conselho da categoria ${ }^{5}$.

O estudo aponta o despreparo e insegurança dos profissionais pesquisados em atuarem neste ramo, pois $47,9 \%$ dos indivíduos afirmaram que, se forem solicitados para atuar como perito não aceitarão por falta de preparo para execução do trabalho e 5,6\% já foram solicitados e também não aceitaram pelo mesmo motivo. Concordando com uma pesquisa realizada com fonoaudiólogos recém-formados do Estado do Rio de Janeiro, onde se encontrou a Perícia como a área em que os Fonoaudiólogos menos pretendem atuar ${ }^{17}$.

A necessidade de Fonoaudiólogos atuando em perícia é fato, porém também há carência de concursos para a inserção destes profissionais e necessidade de maior divulgação desta atuação junto a juízes e promotores. Além disso, os próprios Fonoaudiólogos devem buscar compreender melhor essa área de atuação, pois, na ausência ou falta de fonoaudiólogos atuando em questões que envolvem a comunicação, outros profissionais acabam preenchendo essa lacuna, como no caso dos Estados que não contam com fonoaudiólogos atuando em perícias de identificação de falante e, desta forma, engenheiros, físicos, químicos, biólogos e músicos acabam exercendo a função ${ }^{18}$.

\section{CONCLUSÃO}

Este estudo sinaliza a importância da inserção de matérias específicas para área de perícia em fonoaudiologia dentro do currículo da graduação e cursos de pós-graduação, pois foi possível demonstrar que a perícia em fonoaudiologia é um assunto pouco abordado, fazendo com que os profissionais tenham pouco conhecimento sobre o tema e, em consequência, a atuação na área também se apresenta muito restrita.

Embora a análise esteja limitada aos Estados da Bahia e Paraná, os resultados apontam para a necessidade de outros estudos sobre perícia em fonoaudiologia, para contribuir com maiores investigações e divulgação desse ramo da ciência que configura mais uma possibilidade de atuação dentro da prática fonoaudiológica. 


\section{ABSTRACT}

Purpose: to analyze the knowledge and the performance in speech-language pathology assessment by professionals in two Brazilian states. Method: the study was conducted with 71 male and female speech therapists, aged 21 to 52, working in the states of Bahia and Parana. Their knowledge and performance in speech-language pathology assessment was estimated by applying a questionnaire. Results: we found that $94.4 \%$ of the interviewees are female, aged on average 28 years, graduated for no more than 5 years, and $59.2 \%$ of them have post-graduate certificates. Most of the individuals did not have any contact with assessment during their graduation and few of them took courses on the theme after the completion of the undergraduate programs. Analyzing the other data collected, we verified that the knowledge of the studied population is insufficient in this field and that the speech therapist's performance in assessment is rather restricted. Conclusion: more research and the inclusion of a course on Assessment in Speech-Language Pathology undergraduate and/or graduate programs are extremely important, for assessment was found to be little studied, resulting in a scarse knowledge of it by professionals, which leads to its very restricted conduction among professionals in the area.

KEYWORDS: Speech, Language and Hearing Sciences; Knowledge; Professional Practice Location; Professional Competence; Expert Testimony

\section{REFERÊNCIAS}

1. Cardoso C, Abreu TT. A Fonoaudiologia na Bahia: uma história recente. Revista Baiana de Saúde Pública. 2004;28:96-9. [Acesso em: 4 de Maio de 2012]. Disponível em: http://www.luzimarteixeira. com.br/

2. Paradela ER, Figueiredo ALS. As tipagens por análise de DNA e a sociedade. Revista Dataveni@ (UEPB). 2007;99:1.

3. Santos AGS, Neves Júnior IJ. Um estudo sobre a utilização de pedidos de esclarecimentos como estratégia na Perícia Contábil, na visão de magistrados e peritos contadores do Distrito Federal. RBC-Revista Brasileira de Contabilidade. 2008;37(169):43-53.

4. Prado TAR. A relevância de um laudo pericial contábil elaborado com boa qualidade para as decisões judiciais. Revista CEPPG. 2009;21(2):47-64. [Acesso em: 25 de janeiro de 2012]. Disponível em: http://www.portalcatalao. com/painel_clientes/cesuc/painel/arquivos/upload/ temp/80d08b28f4e5ea3c95faa91fc2e5e13c.pdf

5. Monteiro AL. Perícia em Fonoaudiologia. Jornal do Conselho Federal de Fonoaudiologia. 2002;13:7-8.

6. Peres AS, Peres SHCS, Nishida CL, Grandizoli DK, Ribeiro IWJ, Gobbo LG, Poleti ML. Peritos e perícias em Odontologia. Revista de Odontologiada Universidade Cidade de São Paulo. 2007;19(3):320-4.

7. Resende IC. Fonoaudiologia: Caminhos trilhados na atuação pericial. In: Resende IC. Perícia em fonoaudiologia. Pós - Graduação Lato Sensu Gestão em Fonoaudiologia Perspectiva Empresarial - Módulo III, FEAD: Belo Horizonte; 2008. p. 28 -33. 8. Limongi B, Miguel MAB. O Impacto da Atividade Lúdica no Desempenho de Alunos que Cursam a Disciplina "Perícia Contábil" em Cursos de Graduação em Contabilidade Oferecidos por IES da Grande Florianópolis - SC. Revista Contabilidade Vista \& Revista. 2010;21(3):73-110.

9. Gargaglione MC. Perícia em Fonoaudiologia. [Acesso em: 22 de junho de 2010]. Disponível em: http://www.acadeffor.com.br/artigos/PER\% CDCIA\%20EM\%20FONOAUDIOLOGIA.pdf

10. Bastos AF, Palhares FAB, Monteiro ACC. Medicina legal para não legistas. Campinas: Copola, 1998.

11. Abbud GAC. Perícia em fonoaudiologia. Revista Fono Atual. 2005;8(31):80-1.

12. Resolução do Conselho Nacional de Saúde, no 196 de 10 de outubro de 1996. [Acesso em: 25 de janeiro de 2012]. Disponível em: http://conselho. saude.gov.br/resolucoes/1996/Reso196.doc

13. Silva SLB da, Musse RIP, Nemr K. Assistência domiciliar na cidade de Salvador-BA: possibilidade de atuação fonoaudiológica em Motricidade Orofacial. Rev. CEFAC [online]. 2009;11(1):94101. Epub Mar 06, 2009. ISSN. doi: 10.1590/ S1516-18462009005000001.

14. Almeida LR, Guedes AC, Pereira HS, Neves VD, Nunesmaia MM, Nunesmaia HG. Característica da formação do fonoaudiólogo no estado da Paraíba. Rev Fono Brasil. 2005;3(1):1-3. 
15. Ribas A, Teixeira SB, Luna RCM, Ristow SH, Berberian AP, Massi GA. Perfil do fonoaudiólogo na região sul do Brasil. J Bras Fonoaudiol. 2001;2(6):29-35.

16. Murden BS, Ribas A. Perícia fonoaudiológica a formação para este campo de trabalho no sul do Brasil. Rev Fono Brasil. 2002;2: 45-9.

17. Silva DGM da, Sampaio TMM, Bianchini EMG. Percepçõesdofonoaudiólogorecém-formadoquanto a sua formação, intenção profissional e atualização de conhecimentos. Rev. soc. bras. fonoaudiol. [online]. 2010;15(1):47-53. ISSN 1516-8034. doi: 10.1590/S1516-80342010000100010.

18. Oliveira SMA. Fonoaudiologia Forense. [Acesso em: 25 de janeiro de 2012]. Disponível em: http://www.fonoclinsaude.com.br/noticia.php? cod_noticia $=2$

Recebido em: 18/11/2011

Aceito em: 17/08/2012

Endereço para correspondência:

Leslie Palma Gorski

R. 19 de Dezembro, 538/03, Centro

Irati - PR - Brasil

CEP: 84500-000

E-mail: lesliegorski@yahoo.com.br 